\title{
The Influence of Age and Feedback Training on Ability to Modulate Upper Extremity Weight Bearing Force and Pectoralis Major Muscle Recruitment While Following Sternal Precautions
}

Ansel LaPier ${ }^{1 *}$ and Kimberly Cleary ${ }^{2 \dagger}$

*Correspondence: Lapierlab233@gmail.com

CrossMark

$\leftarrow$ Click for updates

'These authors contributed equally to this work.

Physical Therapy Department, Eastern Washington University, Spokane, Washington USA.

\begin{abstract}
Background: Patients often need to use their arms to assist with functional activities, but frequently after heart surgery performed via median sternotomy upper extremity pushing is limited to $<10 \mathrm{lb}$ to help minimize force across the healing sternum. The main purposes of this study were to determine if during functional mobility older patients less accurately estimated using $<10 \mathrm{lb}$ of arm force than younger ones and if they were able to improve their accuracy following feedback training to the same degree as younger patients.
\end{abstract}

Methods: Force was measured using an instrumented walker and pectoralis major muscle recruitment was measured using electromyography (EMG). Functional mobility tasks included walker ambulation and sit-stand transfers. After baseline testing, subjects $(n=65)$ completed a brief session of visual and auditory concurrent feedback training. Left and right arm data were averaged and the improvement with feedback training was calculated as the absolute difference between pre- and post-data. Statistical analyses included 2-way ANOVA and t-Tests $(\mathrm{P}<0.05)$.

Findings: Results showed that before feedback training mean arm force was $>10$ lb during all functional mobility tasks for both groups. We found significant differences in arm force and EMG between groups (young vs old) and trials (pre- vs post-feedback training). We found significantly greater improvement (change) in arm force in the older compared to younger subjects.

We also found a significantly greater reduction EMG activity in the older subjects than younger subjects for all tasks except during stand-to-sit trials.

Conclusions: Patients, particularly older ones, may not be able to accurately estimate arm force used during weight bearing activities and visual and auditory feedback may improve accuracy and also modulation of pectoralis major muscle activation. Results suggest that an instrumented walker and feedback training could be clinically useful for patients recovering from not only from open heart surgery but also lower extremity surgeries/trauma.

Keywords: Sternal precautions, median sternotomy, feedback training, functional mobility, walker ambulation, open heart surgery

\section{Introduction}

Median sternotomy is frequently used during cardiac surgery because it allows for optimal access to the heart. The procedure entails a longitudinal sternal incision and wiring to reunite the sternal halves after surgery completion [1]. Complications after median sternotomy include superficial and deep wound infections, bony nonunion / sternal instability, and sternal dehiscence which are associated with a variety of risk factors $[2,3]$. Limiting arm activity (known as sternal precautions) to minimize postsurgical stress across the healing sternal halves is thought to reduce the risk of these complications [4,5].

Restricting weighted arm movements to $<10 \mathrm{lb}(4.5 \mathrm{~kg})$ is a common sternal precaution. Purportedly limiting arm activity helps to promote bone healing by minimizing shear and distrac- 
tive forces across the sternum and motion between the sternal edges [3-5]. This significantly limits arm use in numerous daily tasks making it difficult for patients to function independently, especially older adults [6]. Aging is associated with frailty and prolonged functional recovery following cardiac surgery $[\mathbf{7 , 8}]$. This reduction of functional independence can contribute to delayed recovery following cardiac surgery [4-10]. Therefore, appropriate arm use following median sternotomy is important for optimal patient recovery and functional independence.

Few research studies have examined arm weight bearing (WB) force or pectoralis major (PM) muscle activation during functional mobility tasks when patients attempt to limit force to $<10 \mathrm{lb}$ [11-13]. Limited data are available on arm WB force during functional mobility but previous studies have found that it may exceed $>20 \mathrm{lb}(4.5 \mathrm{~kg})[11,12]$ and that more than $12 \mathrm{lb}(5.5 \mathrm{~kg}$ ) of force was employed during most trials (67\%) [13]. In addition, PM muscle activity could provide a good estimation of force across the sternum since it is the primary muscle attached to this bone. Furthermore, the PM muscle has a lateral direction of pull across the sternum, which may have the potential to separate the post-operatively rejoined sternal halves. A previous study found strong intra-subject correlations between arm force and PM muscle EMG activity during functional mobility [13]. The main purposes of this study were to determine if during functional mobility older patients less accurately estimated using $\leq 10 \mathrm{lb}$ of arm WB force than younger ones and if they were able to improve their accuracy following feedback training (FT) to the same degree as younger patients.

\section{Methods}

This study used a within-subjects design with repeated measures. Subjects $(n=65)$ were a convenience sample recruited from a university community via flyers posted around campus and sent electronically (email and text messages). Inclusion criteria were: 1 ) age $18-40$ or $60-85$ years, 2) able to complete Timed Up and Go Test in <14 sec, and 3) able to provide informed consent. Exclusion criteria were: 1 ) recent ( $<6$ months) significant medical event (e.g. stroke, myocardial infarction), 2) pain exacerbated with arm movements / activities, and 3) any contraindication for exercise participation as outlined by the American College of Sports Medicine Guidelines for Exercise Testing [14]. This research project was reviewed and approved by the University's Institutional Review Board and informed consent was obtained from subjects prior to study participation.

Weight bearing forces through the arms were measured using an instrumented walker. Force dynamometers (Jamar Smart, Performance Health, Chicago, IL) were wirelessly connected to tablets (Fire HD 10 Tablet, 1080p Full HD, Amazon, Seattle, WA) and interfaced with an application (Jamar Smart, Performance Health, Chicago, IL) that allowed continuous force data collection for up to $30 \mathrm{sec}$. The dynamometers were attached to the grip holds of a standard walker frame (Deluxe
Two Button Folding Walker Drive, No. 10200-1, Drive Medical, Post Washington, NY) using platform attachments (Platform Walker/Crutch Attachment No. 10105-1, Drive Medical, Post Washington, NY) and $2.5 \mathrm{~cm}$ U-bolts. The front legs of the walker were replaced with wheeled legs (Universal 5"Walker Wheels, Drive Medical, Post Washington, NY) for the front wheeled walker trials. The front legs of the walker could also be replaced with extension legs (Tall Extension Legs, Drive Medical, Post Washington, NY) to accommodate subjects up to $200 \mathrm{~cm}$ tall. During sit-stand transfers the instrumented walker was turned backward and placed behind a stool to simulate a chair with armrests. This configuration created a seat height of $46 \mathrm{~cm}$ and an armrest height of $60 \mathrm{~cm}$.

Surface EMG was used to measure bilateral activity of the PM muscles. Electrodes were placed $3.5 \mathrm{~cm}$ lateral to the anterior axillary line [15]. An additional ground electrode was secured to the study participant's left wrist. The electrodes had dual 1x10 $\mathrm{mm}$, bipolar, silver-silver chloride surfaces, an interelectrode distance of $10 \mathrm{~mm}$, and on-site preamplification with a gain of 1000. They were attached to an EMG data logger (DataLOG Multisensor System MWX8, Biometrics Ltd, Newport, UK) that employed a sampling frequency of $1000 \mathrm{~Hz}$ and a bandwidth of 20 to $450 \mathrm{~Hz}$. Surface EMG data obtained were processed and normalized. Raw EMG signals were analyzed (DataLOG Software, version 8.51, Biometrics Ltd, Newport, UK) and expressed as root-mean-square amplitude which is the square root of the average power of an EMG signal for a given period of time. A data capture window was set for each task between event markers placed during data collection. Normalization of the muscle EMG activity was done by expressing data relative to a maximal voluntary isometric contraction (MVIC) of the PM muscle. This is a commonly accepted method to account for differences in EMG activity measurements between subjects based on muscle mass $[13,15,16]$. A palm press was performed with shoulders flexed 90 degrees bilaterally with the heel of the hands together and elbows flexed 20 degrees as arms were horizontally adducted, as described by Boettcher et al [15]. Subjects held the reference MVIC for $5 \mathrm{sec}$, and the middle $3 \mathrm{sec}$ were used for analysis. The mean of 3 normalization contractions was used for calculating percent MVIC. Subjects rested for $90 \mathrm{sec}$ between each MVIC trial.

Data collection took place while subjects walked with a standard and front wheeled walker and performed sit-stand transfers. Testing took place under 2 different conditions: pre-FT and post-FT. Subjects were instructed to put 5-10 Ib of WB force through each arm during the 4 functional mobility tasks. Walking trials included $>5$ steps and the time capture window was set from the beginning of a heel strike to the beginning of the next one. Transfer trials included 3 repetitions and the time capture window was set from the beginning to the end of each cycle.

A display screen showing real-time force readout provided visual feedback and a buzzer triggered by $>10 \mathrm{lb}$ of force provided auditory feedback. The FT protocol included 
30 sec training sessions repeated once as follows: 1) visual feedback standing in place, 2) auditory feedback during walker ambulation, 3) visual feedback sitting in place, and 4) auditory feedback during sit-stand transfers [13]. Feedback was standardized and consisted of visual force tracing on a tablet screen and buzzer that was activated when force exceeded $10 \mathrm{lb}$. Subjects were tested again immediately after FT. Change from before to after FT training was calculated as the absolute difference between pre-FT and post-FT. Statistical analyses were performed using Excel ToolPak (Microsoft Corporation, Redmond, WA) and included 2-way ANOVA and t-Tests $(P<0.05)$.

\section{Results}

The younger participants $(n=26)$ in this study had a mean $( \pm S D)$ age of $25.3( \pm 2.4)$ years, height of $173.1( \pm 10.7) \mathrm{cm}$, weight of $74.9( \pm 13.7) \mathrm{kg}$, and Body Mass Index of $24.5( \pm 2.7) \mathrm{m} / \mathrm{kg}^{2}$. The older participants $(n=39)$ in this study had a mean $( \pm S D)$ age of $68.6( \pm 6.4)$ years, height of $171.2( \pm 10.0) \mathrm{cm}$, weight of $84.4( \pm 18.1) \mathrm{kg}$, and Body Mass Index of $28.8( \pm 5.8) \mathrm{m} / \mathrm{kg}^{2}$. The younger group had 58\% and the older group had 55\% female participants.

Table 1 contains arm WB force and PM muscle EMG descriptive data. Figures $1 \mathrm{~A}$ and $1 \mathrm{~B}$ illustrate the pre-FT and post-FT force and EMG data, respectively. We found significant differences in force and EMG between groups (young vs old) and trials (before vs after FT). Figure 2 illustrates the degree of improvement in force (A) and EMG (B) after FT for the younger and older subjects. We found significantly greater improvement (change) in arm force in the older compared to younger subjects. We also found a significantly greater improvement in PM muscle recruitment in the older than younger subjects for all tasks except during stand-to-sit trials.

\section{Discussion}

This study set out to determine if age influenced the ability to follow common sternal precautions during functional mobility. Results revealed that during all of the functional tasks performed before FT, subjects WB force exceeded that generally recommended with sternal precautions $(<10 \mathrm{lb})$ $[4,5]$. After FT both groups improved their ability to reduce arm WB force but the older cohort on average still exceeded the $10 \mathrm{lb}$ limit while the younger cohort did not. Other studies have found that with only verbal instructions regarding WB, patients may not be able to accurately estimate extremity WB force [17-18].

In both groups, walking with a front wheeled walker produced less arm WB force than walking with a standard walker. This supports current sternal precautions and general clinical consensus that a front wheeled walker is best for patients after median sternotomy $[\mathbf{4 , 5}$. We found that arm WB force was greater during transfers than walker ambulation. The older cohort used more force during sit-to-stand than standto-sit whereas the younger cohort used similar force during

Table 1. (A) Arm Weight Bearing Force (lb) and (B) Pectoralis Minor Muscle Electromyography (\% Maximal Voluntary Isometric Contraction) Descriptive Data (Mean + SD and Range) for Functional Tasks Pre-Feedback and Post-Feedback Training.

\begin{tabular}{|c|c|c|c|c|}
\hline \multirow[t]{2}{*}{ A) Arm Weight Bearing Force } & \multicolumn{2}{|c|}{ Pre-feedback Training } & \multicolumn{2}{|c|}{ Post-feedback Training } \\
\hline & Young & Old & Young & Old \\
\hline Standard Walker & $\begin{array}{l}19.6 \pm 9.9 \\
(6.0-39.7)\end{array}$ & $\begin{array}{l}\mathbf{2 9 . 4} \pm \mathbf{1 6 . 3}^{\star} \\
(6.7-72.0)\end{array}$ & $\begin{array}{l}\mathbf{1 0 . 2} \pm \mathbf{3 . 1} \dagger \\
(5.3-17.6)\end{array}$ & $\begin{array}{l}\mathbf{1 2 . 7} \pm \mathbf{5 . 3}^{\star} \dagger \\
(5.4-25.0)\end{array}$ \\
\hline Front Wheeled Walker & $\begin{array}{l}\mathbf{1 1 . 9} \pm \mathbf{5 . 6} \\
(2.8-24.6)\end{array}$ & $\begin{array}{l}18.9 \pm \mathbf{9 . 5}^{\star} \\
(3.2-45.8)\end{array}$ & $\begin{array}{l}8.6 \pm 2.6 \dagger \\
(4.4-14.0)\end{array}$ & $\begin{array}{l}\mathbf{1 0 . 4} \pm \mathbf{3 . 3}^{\star} \dagger \\
(4.9-18.7)\end{array}$ \\
\hline Sit to Stand & $\begin{array}{l}18.2 \pm \mathbf{8 . 3} \\
(6.0-37.6)\end{array}$ & $\begin{array}{l}\mathbf{3 6 . 7} \pm \mathbf{1 3 . 5}^{\star} \\
(12.4-68.4)\end{array}$ & $\begin{array}{l}9.8 \pm 3.7 \dagger \\
(5.7-22.4)\end{array}$ & $\begin{array}{l}\mathbf{1 8 . 7} \pm \mathbf{9 . 8}^{\star} \dagger \\
(2.4-49.8)\end{array}$ \\
\hline Stand to Sit & $\begin{array}{l}19.7 \pm 7.5 \\
(6.9-38.8)\end{array}$ & $\begin{array}{l}\mathbf{3 4 . 2} \pm \mathbf{1 4 . 7} \mathbf{7}^{\star} \\
(8.8-64.8)\end{array}$ & $\begin{array}{l}\mathbf{1 0 . 5} \pm \mathbf{3 . 7} \dagger \\
(4.1-18.4)\end{array}$ & $\begin{array}{l}\mathbf{1 7 . 6} \pm \mathbf{9 . 1} \mathbf{1}^{\star} \dagger \\
(3.0-51.0)\end{array}$ \\
\hline \multirow{2}{*}{$\begin{array}{l}\text { B) Pectoralis Muscle } \\
\text { Electromyography }\end{array}$} & \multicolumn{2}{|c|}{ Pre-feedback Training } & \multicolumn{2}{|c|}{ Post-feedback Training } \\
\hline & Young & Old & Young & Old \\
\hline Standard Walker & $\begin{array}{l}4.7 \pm 3.9 \\
(1.1-16.8)\end{array}$ & $\begin{array}{l}\mathbf{1 3 . 9} \pm \mathbf{8 . 7} \\
(1.6-36.8)\end{array}$ & $\begin{array}{l}3.3 \pm 2.6 \dagger \\
(0.7-11.9)\end{array}$ & $\begin{array}{l}9.3 \pm 6.6^{*} \dagger \\
(1.8-26.8)\end{array}$ \\
\hline Front Wheeled Walker & $\begin{array}{l}3.1 \pm 2.8 \\
(0.8-14.4)\end{array}$ & $\begin{array}{l}\mathbf{1 2 . 7} \pm \mathbf{9 . 7} \\
(1.3-38.3)\end{array}$ & $\begin{array}{l}2.7 \pm \mathbf{1 . 8} \dagger \\
(0.5-7.2)\end{array}$ & $\begin{array}{l}9.5 \pm 8.6^{*} \dagger \\
(1.1-35.5)\end{array}$ \\
\hline Sit to Stand & $\begin{array}{l}7.3 \pm 6.5 \\
(0.5-27.7)\end{array}$ & $\begin{array}{l}\mathbf{2 0 . 4} \pm \mathbf{1 2 . 4}^{*} \\
(2.1-50.8)\end{array}$ & $\begin{array}{l}3.1 \pm \mathbf{1 . 8} \dagger \\
(0.6-9.1)\end{array}$ & $\begin{array}{l}\mathbf{1 2 . 9}^{2} \pm \mathbf{1 1 . 3}^{*} \dagger \\
(1.1-51.9)\end{array}$ \\
\hline Stand to Sit & $\begin{array}{l}\mathbf{8 . 4} \pm \mathbf{8 . 0} \\
(0.8-35.0)\end{array}$ & $\begin{array}{l}\mathbf{1 9 . 5}^{\mathbf{1 9}} \mathbf{1 5 . 8}^{\star} \\
(1.2-81.7)\end{array}$ & $\begin{array}{l}3.4 \pm 2.6 \dagger \\
(0.5-10.8)\end{array}$ & $\begin{array}{l}\mathbf{1 3 . 0} \pm \mathbf{1 2 . 2}^{\star} \dagger \\
(1.3-60.2)\end{array}$ \\
\hline
\end{tabular}

*Significant difference young vs old $(\mathrm{P}<0.05)$

$\dagger$ Significant difference pre- vs post-feedback training $(\mathrm{P}<0.05)$ 


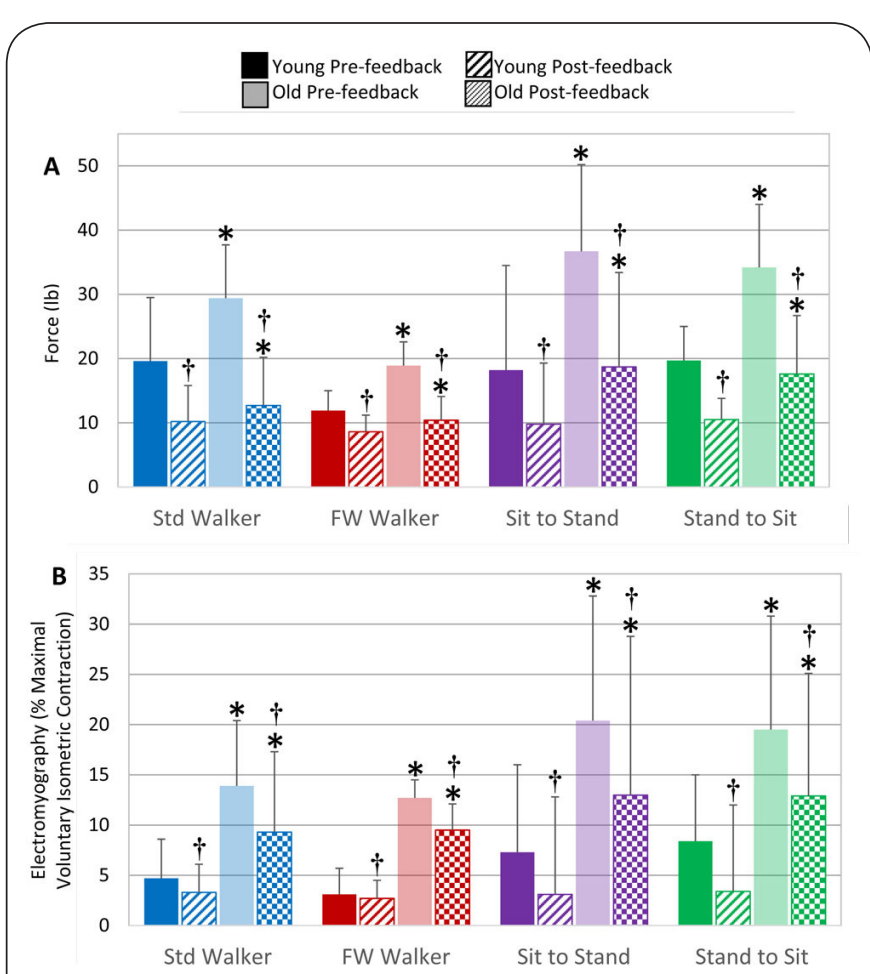

Figure 1. Arm weight bearing force (A) and pectoralis major muscle electromyography $(\mathbf{B})$ data $($ mean \pm SD) before and after feedback training for young and old groups.

Std = standard; FW=front wheeled.

*Significant difference young vs old $(\mathrm{P}<0.05)$.

$\dagger$ Significant difference pre- vs post-feedback training $(\mathrm{P}<0.05)$.

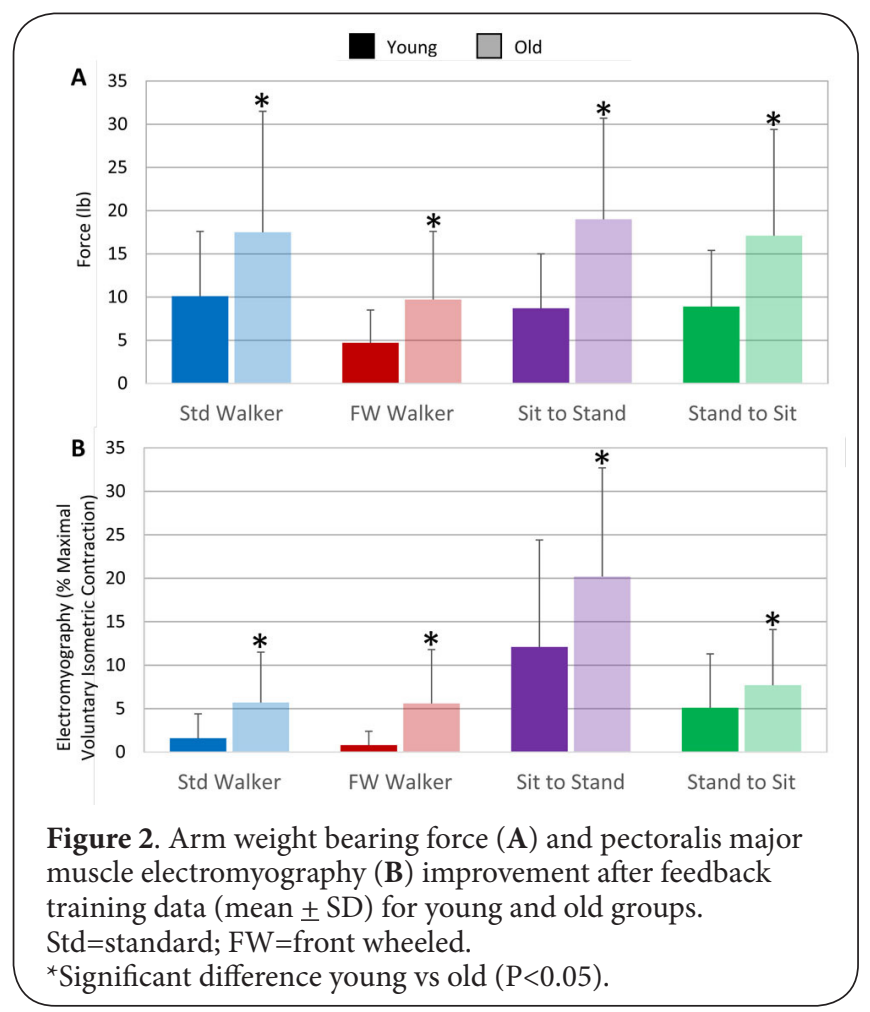

both transfer phases. Perhaps older adults need more arm assistance with the concentric sit-to-stand portion than the eccentric stand-to-sit portion of transfers. Several studies have demonstrated that during sit-stand transfers older adults with global weakness have altered motor planning strategies associated with trunk kinematic changes such as reduced maximum angular velocity and larger angular range [19-21]. Study results demonstrate that a brief feedback intervention can be effective in reducing arm WB force exerted during functional tasks, but more intensive FT (longer and or multiple sessions) would be ideal for older patients.

The PM muscle attaches to the sternal lateral borders, pulls horizontally, and produces horizontal adduction. Results suggest that relative PM muscle activation is greater in older vs younger patients and that FT can reduce it. The EMG data mirrored the force data in this study both before and after FT. It appears older adults may need to use more arm WB force which requires greater PM muscle activation possibly to compensate for leg weakness [22]. This suggests that older adults are recruiting a greater percent of the PM muscle motor units during functional mobility tasks. Fortunately, it seems that when older patients reduce arm WB force this is reflected in PM muscle recruitment following FT training to the same or greater extent than younger patients.

This study had several limitations. Healthy participants were recruited to evaluate the instrumented walker safety and to reduce variability due to post-surgical factors (e.g. pain, impaired cognition). Although, our functionally independent population should be better able to use only $<10 \mathrm{lb}$ of arm WB force than post-surgical populations. Also, arm WB force does not necessarily equal force across the sternum. We used an upper and lower quadrant screen with manual muscle testing to exclude subjects with obvious weakness or asymmetry but did not objectively measure extremity strength so this could be a confounding variable. Lastly, we found benefits only immediately after FT training but did not investigate long-term retention.

\section{Conclusion}

Study results suggest that patients recovering from median sternotomy may not be good at estimating arm WB force $<10$ Ib. However, FT may be effective at reducing arm WB force and possibly stress across the sternum. Overall, study findings suggest that use of an instrumented walker and FT could be beneficial in clinical practice, especially to help older patients more accurately follow WB instructions.

\section{Competing interests}

The authors declare that they have no competing interests. 
LaPier et al, Physical Therapy and Rehabilitation 2021,

\section{Authors' contributions}

\begin{tabular}{|l|c|c|}
\hline Authors' contributions & AL & KC \\
\hline Research concept and design & $\checkmark$ & $\checkmark$ \\
\hline Collection and/or assembly of data & $\checkmark$ & $\checkmark$ \\
\hline Data analysis and interpretation & $\checkmark$ & $\checkmark$ \\
\hline Writing the article & $\checkmark$ & -- \\
\hline Critical revision of the article & $\checkmark$ & $\checkmark$ \\
\hline Final approval of article & $\checkmark$ & -- \\
\hline Statistical analysis & $\checkmark$ & $\checkmark$ \\
\hline
\end{tabular}

\section{Publication history}

Editor: Gordon John Alderink, Grand Valley State University, USA. Received: 05-Nov-2020 Final Revised: 04-Dec-2020

Accepted: 28-Dec-2020 Published: 09-Jan-2021

\section{References}

1. Zubair MH, Smith JM. Updates in minimally invasive cardiac surgery for general surgeons. Surg Clin North Am. 2017;97(4):889-898.

2. Balachandran S, Lee A, Denehy L, Kuan-Yin L, Royse A, Royse C, Al-Ansary D. Risk factors for sternal complications after cardiac operations: a systematic review. Ann Thorac Surg. 2016;102(6):2109-2117.

3. Casha AR, Manche A, Gatt R, Duca E, Gauci M, Schembri-Wismayer P, Camilleri-Podesta M, Grima J. Mechanism of median sternotomy dehiscence. Interact Cardiovasc Thorac Surg. 2014;19(4):617-621.

4. Brocki BC, Thorup CB, Andreasen JJ. Precautions related to midline sternotomy in cardiac surgery: a review of mechanical stress factors leading to sternal complications. Eur J Cardiovasc Nurs. 2010;9(2):77-84.

5. Tuyl LJ, Mackney JH, Johnston CL. Management of sternal precautions following median sternotomy by physical therapists in Australia: a webbased survey. Phys Ther. 2012;92(1):83-97.

6. Min L, Mazzurco L, Gure TR, Cigolle C, Lee P, Bloem, Chan C, Romano M, Nallamothu, Langa K, Prager R, Malani P. Longitudinal functional recovery after geriatric cardiac surgery. J Surg Res. 2015;194(1):25-33.

7. Graham $\mathrm{A}$, Brown $\mathrm{CH}$. Frailty, aging, and cardiovascular surgery. Anesth Analg. 2011;124(4):1053-1060.

8. Guimaraes MN, Filho C. Functional status change in older adults undergoing coronary artery bypass surgery. Sao Paulo Med J. 2011;129(2):99-106.

9. Edgerton JR, Herbert MA, Mahoney C, Armstrong D, Dewey T, Holper E, Roper K, Mack M. Long-term fate of patients discharged to extended care facilities after cardiovascular surgery. Ann Thorac Surg. 2013;96(3):871877.

10. Stocicea N, You T, Eiterman A, Davila V, Marjoribanks S, Florescu C, Bergese $S$, Rogers B. Perspectives of post-acute transition of care for cardiac surgery patients. Front Cardiovasc Med. 2017;27(4):70.

11. Adams J, Cline MJ, Hubbard M, McCullough T, Hartman J. A new paradigm for post-cardiac event resistance exercise guidelines. Am J Cardiol. 2006;97(2):281-286.

12. Swanson LB, Kinney LaPier T. Upper extremity forces generated during activities of daily living. J Acute Care Phys Ther. 2014;5(2):70-76.

13. LaPier A, Cleary K. Feedback training improves accuracy of estimating upper extremity weight bearing during functional tasks: implications after open heart surgery. Int J Physiother Res. 2019;7(4):3163-3172. DOI:10.16965/ijpr.2019.151

14. Riebe D, Ehrman JK, Liguori G, Magal M, American College of Sports Medicine. ACSM's Guidelines for Exercise Testing and Prescription. Philadelphia, PA: Wolters Kluwer, 2018.

15. Boettcher CE, Ginn KA, Cathers I. Standard maximum isometric voluntary contraction test for normalizing shoulder muscle EMG. J Orthop Res. 2008;26:1591-1597.

16. Gruevski KM, Hodder JN, Keir PJ. Upper extremity muscle activity during in-pase and anti-phase continuous pushing tasks. Human Factors.
2017;59(7):1066-1077.

17. Ruiz FK, Fu MC, BohI DD, Hustedt J, Baumgaertner M, Leslie M, Grauer J. Patient compliance with postoperative lower extremity touch down weight bearing orders at a level I trauma center. Orthop. 2014;37(6):e552-556.

18. Hustedt JW, Blizzard DJ, Baumgaertner MR, Leslie MP, Grauer JN. Effect of age on partial weight-bearing training. Orthop. 2012;35(7):e1061-1067.

19. Anglin C, Wyss UP. Arm motion and load analysis of sit-to-stand, stand-tosit, and walking and lifting. Clin Biomech. 2000;15:441-448.

20. Hassani A, Kubicki A, Brost V, Mourey F, Yang F. Kinematic analysis of motor strategies in frail aged adults during the Timed Up and Go: how to spot the motor frailty? Clinic Interven Age. 2015;10:505-513.

21. van Lummel RC, Evers J, Niessen M, Beek PJ, van Dieen JH. Older adults with weaker muscle strength stand up from a sitting position with more dynamic trunk use. Sensors. 2018;18:1235; doi:10.3390 / s18041235

22. van Venrooij LM, Verberne HJ, de Vos R, Borgmeijer-Hoelen M, van Leeuwen P, de Mol B. Postoperative loss of skeletal muscle mass, complications and quality of life in patients undergoing cardiac surgery. Nutrition. 2012;28(1):40-45.

\section{Citation:}

LaPier A and Cleary K. The Influence of Age and Feedback Training on Ability to Modulate Upper Extremity Weight Bearing Force and Pectoralis Major Muscle Recruitment While Following Sternal Precautions. Phys Ther Rehabil. 2021; 8:1. http://dx.doi.org/10.7243/2055-2386-8-1 